\title{
Iron Formulations for the Treatment of Iron Deficiency Anemia in Patients with Inflammatory Bowel Disease: A Cost-Effectiveness Analysis in Switzerland
}

Aysegül Aksan · Alain Schoepfer · Pascal Juillerat - Stephan Vavricka •

Miguel Bettencourt - Antonio Ramirez de Arellano · Simona Gavata ·

Neige Morin $\cdot$ William J. Valentine $\cdot$ Barnaby Hunt (B)

Received: September 28, 2020 / Accepted: October 24, 2020 / Published online: November 20, 2020

(C) The Author(s) 2020

\section{ABSTRACT}

Introduction: Iron deficiency anemia (IDA) is a common complication of inflammatory bowel disease (IBD) and can result in reduced quality of life and increased healthcare costs. IDA is treated with iron supplementation, either with

A. Aksan

Interdisciplinary Crohn Colitis Centre, Rhein-Main, Frankfurt/Main, Germany

A. Aksan

Justus-Liebig University, Giessen, Germany

A. Schoepfer

Division of Gastroenterology and Hepatology,

Centre Hospitalier Universitaire de Lausanne and

University of Lausanne, Lausanne, Switzerland

P. Juillerat

Gastroenterology, Clinic of Visceral Surgery and

Medicine, Bern University Hospital, Bern,

Switzerland

S. Vavricka

Zentrum für Gastroenterologie und Hepatologie,

Zürich, Switzerland

M. Bettencourt · N. Morin

Vifor Pharma Group, Villars-sur-Glâne, Switzerland

A. Ramirez de Arellano $(\bowtie) \cdot$ S. Gavata

Vifor Pharma Group, Glattbrugg, Switzerland

e-mail: antonio.ramirez@viforpharma.com

W. J. Valentine $\cdot$ B. Hunt

Ossian Health Economics and Communications,

Basel, Switzerland oral iron therapy (OI) or intravenous iron formulations, including ferric carboxymaltose (FCM), iron isomaltoside 1000 (IIM), and iron sucrose (IS). This analysis compared the costeffectiveness of FCM versus IIM, IS, and OI in terms of additional cost per additional responder in Switzerland.

Methods: A health economic model was developed to assess the additional cost per additional responder, defined as normalization or an increase of at least $2 \mathrm{~g} / \mathrm{dL}$ in hemoglobin levels, for FCM versus IIM, IS, and OI. To date, no single head-to-head trial comparing all therapies is available, and therefore relative efficacy data were taken from a published network meta-analysis. Costs of treatment were calculated in 2020 Swiss francs (CHF) using a microcosting approach, and included the costs of iron, healthcare professional time, and consumables. Costs are also presented in euros (EUR) based on an exchange rate of CHF 1 = EUR 0.94.

Results: Response rates with FCM, IIM, IS, and OI were $81 \%, 74 \%, 75 \%$, and $69 \%$, respectively, with FCM projected to be the most effective treatment. FCM was associated with cost savings of CHF 24 (EUR 23) versus IIM and of CHF 147 (EUR 138) versus IS, and increased costs by CHF 345 (EUR 324) versus OI. Therefore FCM was considered dominant versus both IIM and IS, improving clinical outcomes with cost savings. FCM was associated with an incremental 
cost-effectiveness ratio of CHF 2970 (EUR 2792) per additional responder versus OI.

Conclusions: FCM was projected to be the most cost-effective intravenous iron therapy in Switzerland, increasing the number of responders and leading to cost savings for healthcare payers.

Keywords: Cost; Cost-effectiveness; Inflammatory bowel disease; Iron deficiency anemia; Switzerland

\section{Key Summary Points}

Why carry out this study?

Iron deficiency anemia (IDA) subsequent to inflammatory bowel disease (IBD) is associated with reduced quality of life, an increase in time off work, an increased frequency of hospitalization, and increased healthcare costs.

Treatment options for IDA subsequent to IBD include oral and intravenous iron formulations, with ferric carboxymaltose (FCM), iron isomaltoside 1000 (IIM), and iron sucrose (IS) currently available in Switzerland.

The present analysis compared the costeffectiveness, expressed in terms of additional cost per additional responder, of FCM versus IIM, IS, and oral iron therapy in Switzerland, based on the differing costs and dosing profiles, and the differences in clinical efficacy identified in the recently published network metaanalysis (NMA).

\section{What was learned from the study?}

FCM was considered dominant versus both IIM and IS, improving clinical outcomes with cost savings.

FCM was associated with an incremental cost-effectiveness ratio of CHF 2970 (EUR 2792) per additional responder versus oral iron therapy.

\section{DIGITAL FEATURES}

This article is published with digital features, including a summary slide, to facilitate understanding of the article. To view digital features for this article go to https://doi.org/10.6084/ m9.figshare.13135580.

\section{INTRODUCTION}

Inflammatory bowel disease (IBD) is a group of conditions involving chronic inflammation of the digestive tract, the most common of which are Crohn's disease and ulcerative colitis. A global study of the prevalence of IBD estimated the prevalence in Switzerland to be 94.8 cases per 100,000 population, while an analysis of gastroenterologist files in the canton of Vaud suggests that the prevalence of IBD is much higher at 205.7 cases per 100,000 population (comprised of 100.7 cases of Crohn's disease per 100,000 population and 105.0 cases of ulcerative colitis per 100,000 population) [1, 2]. Analysis of insurance data suggests that approximately $25 \%$ of patients with IBD are hospitalized annually, compared with approximately $10 \%$ of the population without IBD [3]. Anemia is the most frequent complication of IBD and has been shown to negatively impact quality of life and cognitive function $[4,5]$. In the majority of cases of anemia subsequent to IBD, the cause is a combination of iron deficiency anemia (IDA) and anemia of chronic disease (ACD) [6]. It is estimated that iron deficiency occurs in between $36 \%$ and $90 \%$ of patients with anemia with IBD [7]. Iron deficiency and IDA result from a combination of factors, including chronic blood loss from the intestinal mucosa, impaired gastrointestinal absorption (sometimes due to short bowel syndrome), reduced dietary intake due to loss of appetite, and blockage of intestinal iron acquisition $[8,9]$. IDA subsequent to IBD is associated with reduced quality of life, an increase in time off work, an increased frequency of hospitalization, and increased healthcare costs [10].

The aims of iron supplementation in patients with IDA subsequent to IBD, based on guidelines released by the European Crohn's 
and Colitis Organisation (ECCO) and published in the World Journal of Gastrointestinal Pathophysiology, are to replenish iron stores, normalize levels of hemoglobin, serum ferritin, and transferrin saturation, avoid the need for blood transfusion, and improve quality of life $[11,12]$. Available treatment options to achieve these goals include oral and intravenous (IV) iron formulations. Oral iron therapy is recommended for patients with mild IDA and clinically inactive IBD, with no history of intolerance to oral iron administration [11]. The key advantages of oral iron therapy are the low cost and ease of administration at home. However, efficacy is limited because of impaired intestinal iron absorption due to the underlying IBD, and side effects, such as abdominal pain, nausea, bloating, and diarrhea, can limit adherence. Furthermore, oral iron therapy can exacerbate IBD, with unabsorbed iron causing mucosal damage, generation of reactive oxygen species causing oxidative stress in the intestinal tract, and alteration of the gut microbiota [13-16]. IV iron products are recommended for patients with severe anemia (hemoglobin less than $10 \mathrm{~g} / \mathrm{dL}$ ), intolerance or lack of response to oral iron therapy, active IBD, or where there is a need for a quicker response and/or longer-term iron supplementation [11, 12]. IV iron therapy has been shown to be more effective in terms of iron replenishment than oral iron therapy. Additionally, the avoidance of gastrointestinal side effects allows administration in patients with active IBD. However, administration of IV iron products is only possible in a medical facility (hospital or perfusion unit in a private practice), and while adverse events with modern formulations are rarely severe, immediate access to resuscitation equipment is required [11]. The IV iron therapies currently available in Switzerland are ferric carboxymaltose (FCM) (Ferinject $^{\circledR}$, Vifor Pharma Group), ferric derisomaltose/iron isomaltoside 1000 (IIM) (Monofer $^{\circledR}$, Pharmacosmos A/S), and iron sucrose (IS) (Venofer ${ }^{\circledR}$, Vifor Pharma Group).

Each IV iron formulation has a specific dosing pattern and schedule outlined in each of the product labels, resulting in different delivery patterns in clinical practice. FCM can be administered in doses up to $1000 \mathrm{mg}$ iron in a single infusion [17]. When IIM is used, up to $20 \mathrm{mg}$ of iron can be administered per kilogram of body weight (e.g., $1000 \mathrm{mg}$ of iron can be administered in a patient weighing $50 \mathrm{~kg}$, but $1200 \mathrm{mg}$ of iron can be administered in a patient weighing $60 \mathrm{~kg}$ ) [18]. In contrast, IS dosing is limited to $200 \mathrm{mg}$ iron per infusion [19]. A number of studies have compared FCM with IIM, FCM with IS, and FCM, IIM, and IS, individually, with oral iron therapy, but no single trial has compared the efficacy and safety of all possible treatment options in a single population [20-26]. However, Aksan et al. conducted a network meta-analysis (NMA) in which the outcomes from the four existing randomized controlled trials (RCTs) of FCM, IIM, IS, and oral iron therapy were combined and adjusted for differences in study populations and trial methods [27]. The NMA assessed the dichotomous variable of treatment response, where a response was defined in line with ECCO guidelines as normalization of hemoglobin levels or an increase of at least $2 \mathrm{~g} /$ $\mathrm{dL}$ in hemoglobin. This analysis found that FCM was significantly more efficacious than oral iron therapy and was associated with a numerically greater but not statistically significant increase in response rate compared with IIM and IS (Table 1). Rank probability assessment found that there was an $83 \%$ probability that FCM was the most effective treatment, with a $14 \%$ probability that IIM was the most effective treatment.

As part of evidence-based healthcare decision-making, analyses not only of efficacy and safety but also of value for money are increasingly taken into account. Cost-utility analyses take into account costs and qualityadjusted life expectancy with a new intervention versus current practice, with the aim of calculating an incremental cost-effectiveness ratio (ICER), describing the additional cost per additional quality-adjusted life year (QALY) gained [28]: 


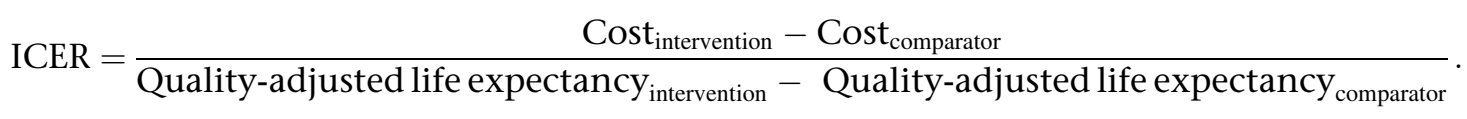

The calculated ICER can then be compared with a willingness to pay threshold, to evaluate whether the new intervention would be considered good value for money if used in clinical practice. While cost-utility analyses are considered the gold standard, robust sources of information on how treatments affect quality of life are required. To date, data on how treatments for IDA affect quality of life in patients with IBD are not available. In such situations, it is recommended that cost-effectiveness analyses are performed, assessing outcomes in terms of "natural units". For example, a screening program could be assessed on the basis of "cost per case detected", while a fertility treatment could be assessed on the basis of "cost per live birth" $[29,30]$. When the cost-effectiveness of interventions for IDA is assessed, the "natural unit" of "number of patients responding to treatment" could be used. The ICER formula can be adapted to become expressed in terms of additional cost per additional responder, of FCM versus IIM, IS, and oral iron therapy in Switzerland, based on the differing costs and dosing profiles, and the differences in clinical efficacy identified in the recently published NMA [27].

\section{METHODS}

\section{Approach to Estimating Cost-Effectiveness}

Cost-effectiveness was estimated in terms of the additional cost per additional responder with FCM versus IIM, IS, and oral iron therapy individually over one cycle of treatment, where a responder was defined on the basis of the ECCO guidelines as achieving hemoglobin normalization or an increase of at least $2 \mathrm{~g} / \mathrm{dL}$ in hemoglobin levels. Evaluation of the dichotomous variable "response versus no response" was

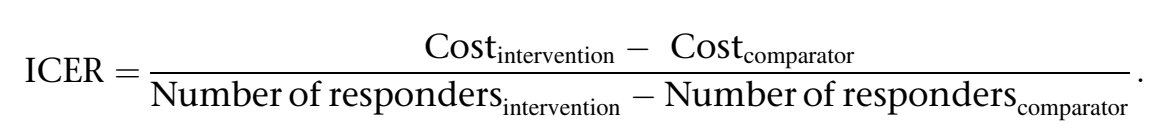

While there is no willingness to pay threshold for the additional cost per additional responder, this approach provides context on the relative cost-effectiveness of IDA treatments in patients with IBD, which would not otherwise be possible, thereby providing useful information to healthcare decision makers.

To date, no analyses have assessed the costeffectiveness of iron treatments for patients with IDA subsequent to IBD in Switzerland. The present analysis aimed to address this research question, comparing the cost-effectiveness, considered an appropriate parameter to measure efficacy, as use of a continuous variable, such as mean hemoglobin increase, can be influenced by baseline hemoglobin levels. A cost-effectiveness model was prepared in Microsoft Excel to calculate costs and the percentage of patients with IBD and IDA achieving a response, with FCM, IIM, IS, and oral iron therapy. To do this, the model generated a cohort of patients with IDA and IBD, with patient characteristics sampled based on defined distributions. This probabilistic 
Table 1 Treatment efficacy: odds ratio for response rate

\begin{tabular}{llll}
\hline & $\begin{array}{l}\text { Odds ratio compared with ferric } \\
\text { carboxymaltose }\end{array}$ & $\begin{array}{l}\text { Lower 95\% credible } \\
\text { interval }\end{array}$ & $\begin{array}{l}\text { Upper 95\% credible } \\
\text { interval }\end{array}$ \\
\hline $\begin{array}{l}\text { Iron } \\
\text { isomaltoside }\end{array}$ & 0.69 & 0.34 & 1.40 \\
Iron sucrose & 0.70 & 0.48 & 1.00 \\
$\begin{array}{l}\text { Oral iron } \\
\text { therapy }\end{array}$ & 0.53 & 0.32 & 0.89 \\
\hline
\end{tabular}

Response was defined as a patient who achieved normalization of hemoglobin levels or an increase in hemoglobin of at least $2 \mathrm{~g} / \mathrm{dL}[27]$

approach, rather than simply using mean values, allows a representative cohort of patients with differing characteristics and therefore different iron requirements and different costs of treatment to be used, as well as capturing the uncertainty around differences in efficacy between treatment arms identified by the Aksan et al. NMA. It results in a spread of cost and efficacy values, the mean and standard error (SE) of which can be calculated. A total of 1000 patients were simulated, with characteristics sampled for each patient, as outcomes were stable at this number of model iterations. Outcomes were not projected beyond a 1-year time horizon, and therefore no discounting was applied.

\section{Calculation of Costs}

Cost of a course of treatment for IDA in patients with IBD was calculated for each of the 1000 patients with the four interventions in 2020 Swiss francs (CHF). Costs are also presented in euros (EUR) based on an exchange rate of CHF $1=$ EUR 0.94. In each model iteration, patient hemoglobin and body weight were sampled based on the two RCTs of FCM included in the NMA $[22,23]$. The mean hemoglobin across the two RCTs was $9.6 \mathrm{~g} / \mathrm{dL}$ with a standard error (SE) $0.1 \mathrm{~g} / \mathrm{dL}$, while the mean body weight was $66.6 \mathrm{~kg}$ with an SE of $0.7 \mathrm{~kg}$. In each iteration, the sampled patient characteristics were used to calculate the required iron dose. With FCM this was calculated using the Ganzoni formula, as is recommended in the prescribing information in
Switzerland [17]. The formula takes into account patient body weight, hemoglobin, target hemoglobin, and iron stores, with iron stores assumed to be $500 \mathrm{mg}$ and target hemoglobin assumed to be $15 \mathrm{mg} / \mathrm{dL}$ in all patients:

$$
\begin{aligned}
\operatorname{Iron} \text { deficit }(\mathrm{mg})= & \text { body weight } \\
& \times(\text { target } \mathrm{Hb}-\mathrm{Hb}) \times 2.4 \\
& + \text { iron stores. }
\end{aligned}
$$

In the IIM and IS arms, the simplified dosing table was used to calculate the required dose (Table 2), as recommended in the ECCO anemia guidelines [12]. Following calculation of the appropriate iron dose, the number of infusions required to deliver the dose was calculated based on each of the product labels [17-19].

Costs of infusion of iron were calculated using a microcosting approach, where the unit costs of each aspect of medical resource use are summed to give a total cost. Therefore costs were calculated from a hospital perspective. The

Table 2 Simplified dosing table

\begin{tabular}{llrr}
\hline Hemoglobin $(\mathrm{g} / \mathrm{dL})$ & \multicolumn{3}{l}{ Body weight $(\mathbf{k g})$} \\
\cline { 2 - 4 } & $<\mathbf{3 5}$ & $\mathbf{3 5 - 7 0}$ & $\mathbf{2 7 0}$ \\
\hline$<10$ & 500 & 1500 & 2000 \\
$10-14$ & 500 & 1000 & 1500 \\
$\geq 14$ & 500 & 500 & 500 \\
\hline
\end{tabular}

Response was defined as a patient who achieved normalization of hemoglobin levels or an increase in hemoglobin of at least $2 \mathrm{~g} / \mathrm{dL}$ 
Table 3 Pack contents and pack costs of IV iron formulations

\begin{tabular}{llcl}
\hline & Pack contents & Pack cost $(\mathbf{C H F})$ & Cost per mg iron $(\mathbf{C H F})$ \\
\hline Ferric carboxymaltose & 5 vials each containing $100 \mathrm{mg}$ iron & 28.05 & 0.28 \\
Ferric carboxymaltose & 5 vials each containing $500 \mathrm{mg}$ iron & 140.25 & 0.28 \\
Ferric carboxymaltose & 1 vial containing $1000 \mathrm{mg}$ iron & 280.50 & 0.28 \\
Iron isomaltoside & 5 vials each containing $100 \mathrm{mg}$ iron & 26.87 & 0.27 \\
Iron isomaltoside & 5 vials each containing $500 \mathrm{mg}$ iron & 134.33 & 0.27 \\
Iron isomaltoside & 2 vials containing $1000 \mathrm{mg}$ iron & 268.67 & 0.27 \\
Iron sucrose & 5 vials each containing $100 \mathrm{mg}$ iron & 16.93 & 0.17 \\
\hline
\end{tabular}

CHF 2020 Swiss francs

Table 4 Resource use associated with infusion of IV iron formulations

\begin{tabular}{llll}
\hline & Ferric carboxymaltose & Iron isomaltoside & Iron sucrose \\
\hline Infusion time (minutes) & & & - \\
$<500 \mathrm{mg}$ & 6 & - & - \\
$500-1000 \mathrm{mg}$ & 15 & - & - \\
$<1000 \mathrm{mg}$ & - & 15 & - \\
$>1000 \mathrm{mg}$ & - & 30 & 8 \\
$<50 \mathrm{mg}$ & - & - & 15 \\
$50-100 \mathrm{mg}$ & - & - & 30 \\
$100-200 \mathrm{mg}$ & - & - & 15 \\
Preparation time (min) & 15 & 15 & 30 \\
Observation time (min) & 30 & 30 & 1 \\
Giving sets required & 1 & 1 & 1 \\
Cannula required & 1 & 1 & 1 \\
Dressings required & 1 & 1 & \\
\hline
\end{tabular}

pharmacy costs associated with FCM, IIM, and IS were based on ex-factory prices (Table 3) [31]. It was assumed that vials of IV iron product were used in the most cost-efficient manner, with the most appropriate vial or combination of vials used to deliver the required dose at the lowest possible cost. Where a required dose was less than the complete contents of a vial, the remainder of that vial was assumed to be wasted. In addition to the pharmacy costs, the cost calculation also captured the costs of time required by a healthcare professional to deliver the infusion (based on the label for each product, capturing preparation time, infusion time, and post-infusion supervision), giving sets, cannula, and dressings (Table 4) [32-35]. The total cost per course of treatment was then 
calculated by summing the cost of all infusions with each iron formulation.

The cost of oral iron was calculated based on a 15-min consultation with a general practitioner, a laboratory blood test, and an 84-day course of $100 \mathrm{mg}$ ferrous sulfate administered orally twice daily [31, 36, 37]. This dosing reflected the oral iron therapy arm of the RCT included in the NMA which compared FCM with oral iron therapy [23]. Other studies captured by the NMA applied various durations of oral iron therapy, with the study comparing IS and oral iron therapy applying a dosing schedule of $100 \mathrm{mg}$ ferrous sulfate administered orally twice daily for 20 weeks, and the studies comparing ISM and IS with oral iron therapy using schedules of 100-200 mg of ferrous sulfate for 8 weeks. Therefore matching to the FCM versus oral iron therapy RCT reflected the average of the trials included in the NMA.

\section{Calculation of Efficacy}

Efficacy was expressed in terms of the percentage of patients achieving a response over one cycle of treatment, where a responder was defined based on the ECCO guidelines as achieving hemoglobin normalization or an increase of at least $2 \mathrm{~g} / \mathrm{dL}$ in hemoglobin levels. In the FCM arm this was based on the weighted average of the two RCTs of FCM captured in the Aksan et al. NMA [22, 23, 27]. Over these two trials, $81 \%$ of patients receiving FCM achieved a response. In each model iteration, this was sampled based on an SE of $2.1 \%$, derived assuming a binomial proportion confidence interval. To calculate the percentage of patients achieving a response with IIM, IS, and oral iron therapy, the odds ratio for each comparator versus FCM was sampled based on the mean and $95 \%$ credible interval (CI) calculated by Aksan et al. (Table 1). The mean and SE of patients achieving a response was calculated for each therapy across all of the model iterations. Differences between the mean percentages of responders were used to calculate the number needed to treat, expressed as the number of patients who would need to be treated with FCM instead of the comparator in order to achieve one additional responder. Number needed to treat values are conventionally rounded up to the next integer value.

\section{Calculation of Cost-Effectiveness}

The cost-effectiveness of FCM was assessed versus each of IIM, IS, and oral iron therapy in turn, with ICERs expressed in terms of additional cost per additional responder. In each comparison, the mean cost of a course of treatment with each intervention was subtracted from the mean cost of a course of treatment with FCM, and the mean percentage of responders with each comparator was subtracted from the mean percentage of responders with FCM. The cost difference was divided by the difference in response rates to calculate the ICER. In a cost-effectiveness analysis, an intervention that is both more effective and results in reduced costs is described as "dominant", and calculation of an ICER is not appropriate (i.e., negative ICERs should not be reported). Therefore, in comparisons where FCM was projected to increase response rates and decrease costs compared with an alternative intervention, no ICER was calculated.

\section{Scenario Analyses}

To evaluate the impact of different methods of estimating the iron requirement and calculating costs, a series of scenario analyses were performed. In the base case analysis, the Ganzoni formula was applied in the FCM arm, with the simplified dosing table used in the IIM and IS arms. In a scenario analysis, the Ganzoni formula was applied in all arms.

An alternative to the microcosting approach was also explored. In Switzerland, TARMED codes can be used by healthcare providers to bill their medical activities in an outpatient setting to insurance companies. These codes take into account healthcare professional time, as well as fixed costs of running hospitals/practices. These codes cover provision of services, but do not include costs of medications, and therefore these costs were included using the same methodology as the base case analysis. Analyses 
were conducted with TARMED codes applied and the Ganzoni formula used in the FCM arm and the simplified dosing table used in the IIM and IS arms, and with the Ganzoni formula used in all arms. In these analyses, costs were assessed from an insurance company perspective.

\section{Sensitivity Analyses}

As well as the scenario analyses, a series of sensitivity analyses were conducted to evaluate the robustness of the model results and the impact of variation in model inputs. The effect of varying the odds ratios taken from the NMA was assessed by preparing analyses with the upper and lower 95\% CIs of the odds ratios for achieving a response with the comparator versus FCM. This aims to capture the uncertainty around the outcomes of the NMA. Body weight and hemoglobin are the key determinants of the iron dose required, both when the Ganzoni formula and when the simplified dosing table are used. Therefore sensitivity analyses were performed with the mean body weight increased by 10 (i.e., to $76.6 \mathrm{~kg}$ ), and with the mean hemoglobin increased and decreased by $1 \mathrm{~g} / \mathrm{dL}$. In addition, there may be greater variation between patients with IBD in real-world clinical practice than in an RCT, and to assess the importance of this, an analysis was prepared with the SEs around mean body weight and hemoglobin increased to $10 \%$ of the mean. To investigate the sensitivity of the analysis to changes in the pharmacy costs, two analyses were performed with variation in these model inputs. In the first, all pharmacy costs were increased by $10 \%$, while in the second, all pharmacy costs were decreased by $10 \%$.

\section{Compliance with Ethics Guidelines}

This article is based on previously conducted studies and does not contain any studies with human participants or animals performed by any of the authors.

\section{RESULTS}

\section{Base Case Analysis}

The modeling analysis suggested that FCM was the most effective intervention, with $81 \%$ (SE $2 \%$ ) of patients with IBD-associated IDA responding to treatment with this therapy. IIM and IS were associated with similar efficacy, with 74\% (SE 6\%) and 75\% (SE 4\%) of patients achieving a response, respectively. A total of $69 \%$ (SE 4\%) of patients responded to treatment with oral iron therapy, suggesting that it is the least effective treatment option. When expressed as number needed to treat in order to achieve one additional responder with FCM, 16, 17 , and 9 patients would need to switch treatment from IIM, IS, and oral iron therapy, respectively (Fig. 1). Higher number needed to treat values reflect smaller differences between the compared groups.

The required dose of iron varied across the IV iron preparations because of the different calculation methods used. In the FCM arm, a mean dose of $1364 \mathrm{mg}$ (SE $17 \mathrm{mg}$ ) was required, compared with $1500 \mathrm{mg}$ with both IIM and IS. However, the mean number of infusions required to deliver the appropriate dose was equal in the FCM and IIM arms, with all simulated patients requiring two infusions. In the IS arm, all patients required eight infusions to deliver the required dose of iron. Assessment of costs across the four treatment arms found that the mean cost of a course of treatment was CHF 461 (EUR 433) with FCM, CHF 485 (EUR 456) with IIM, CHF 608 (EUR 572) with IS, and CHF 115 (EUR 108) with oral iron therapy. Therefore FCM was associated with cost savings of CHF 24 (EUR 23) versus IIM and of CHF 147 (EUR 138) versus IS, and increased costs by CHF 345 (EUR $325)$ versus oral iron therapy. Cost savings with FCM were driven by the lower dose of iron required versus IIM and by the reduced number of infusions, and therefore reduced requirement for hospital-based healthcare professional time and consumables, versus IS.

Combining projections of response rates and treatment costs showed that FCM was more effective and less costly than both IIM and IS. 


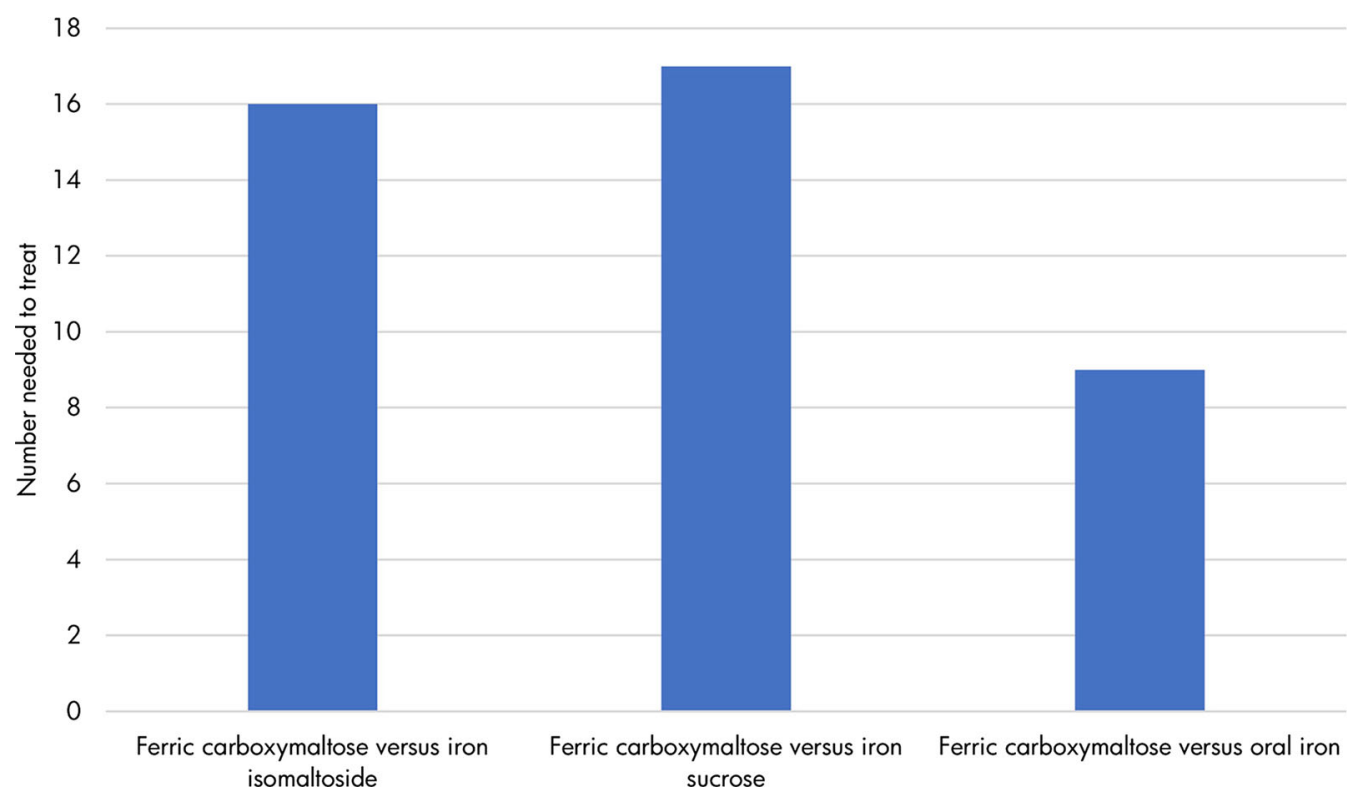

Fig. 1 Number needed to treat to achieve one additional responder with ferric carboxymaltose versus other therapy options. Number needed to treat was expressed as the number of patients who would need to be treated with ferric carboxymaltose instead of the comparator in order to achieve one additional responder. Number needed to treat values are conventionally rounded up to the next integer value

Table 5 Results of the base case modeling analysis

\begin{tabular}{|c|c|c|c|c|}
\hline & $\begin{array}{l}\text { Ferric } \\
\text { carboxymaltose }\end{array}$ & Iron isomaltoside & Iron sucrose & $\begin{array}{l}\text { Oral iron } \\
\text { therapy }\end{array}$ \\
\hline Responders (\%) & $81(2)$ & $74(6)$ & $75(4)$ & $69(4)$ \\
\hline Iron dose (mg) & $1364(17)$ & $1500(0)$ & $1500(0)$ & - \\
\hline Number of infusions & $2.0(0.0)$ & $2.0(0.0)$ & $8.0(0.0)$ & - \\
\hline Cost of treatment (CHF) & $461(3)$ & $485(0)$ & $608(0)$ & $115(0)$ \\
\hline $\begin{array}{l}\text { Additional cost per additional } \\
\text { responder with ferric } \\
\text { carboxymaltose versus the } \\
\text { comparator }\end{array}$ & & $\begin{array}{l}\text { Ferric carboxymaltose } \\
\text { more effective and } \\
\text { less costly }\end{array}$ & $\begin{array}{l}\text { Ferric carboxymaltose } \\
\text { more effective and } \\
\text { less costly }\end{array}$ & $\begin{array}{l}\text { CHF } 2970 \text { per } \\
\text { additional } \\
\text { responder }\end{array}$ \\
\hline
\end{tabular}

Response was defined as a patient who achieved normalization of hemoglobin levels or an increase in hemoglobin of at least $2 \mathrm{~g} / \mathrm{dL}$. Values are mean (standard error)

CHF 2020 Swiss francs

Therefore, calculation of ICERs was not required, and FCM was considered dominant versus both IIM and IS. In the comparison of oral iron therapy, FCM was associated with an increased number of responders at an increased cost, resulting in an ICER of CHF 2970 (EUR 2792) per additional responder (Table 5).

\section{Scenario Analyses}

When the Ganzoni formula (instead of the simplified dosing table) was used to estimate the required iron dose in the IIM and IS arms, the required dose fell in both these treatment arms. The mean number of infusions required with 
Table 6 Scenario analysis results

\begin{tabular}{|c|c|c|c|}
\hline & \multicolumn{3}{|c|}{$\begin{array}{l}\text { Additional cost per additional responder with ferric } \\
\text { carboxymaltose versus the comparator }\end{array}$} \\
\hline & $\begin{array}{l}\text { Ferric } \\
\text { carboxymaltose } \\
\text { versus iron } \\
\text { isomaltoside }\end{array}$ & $\begin{array}{l}\text { Ferric } \\
\text { carboxymaltose } \\
\text { versus iron sucrose }\end{array}$ & $\begin{array}{l}\text { Ferric } \\
\text { carboxymaltose } \\
\text { versus oral iron } \\
\text { therapy }\end{array}$ \\
\hline \multicolumn{4}{|l|}{ Microcosting approach } \\
\hline $\begin{array}{l}\text { Base case analysis (Ganzoni formula used in the } \\
\text { ferric carboxymaltose arm, simplified dosing } \\
\text { table used in iron isomaltoside and iron sucrose } \\
\text { arms) }\end{array}$ & $\begin{array}{l}\text { Ferric carboxymaltose } \\
\text { more effective and } \\
\text { less costly }\end{array}$ & $\begin{array}{l}\text { Ferric carboxymaltose } \\
\text { more effective and } \\
\text { less costly }\end{array}$ & $\begin{array}{l}\text { CHF } 2970 \text { per } \\
\text { additional } \\
\text { responder }\end{array}$ \\
\hline Ganzoni formula used in all arms & $\begin{array}{l}\text { CHF } 45 \text { per } \\
\text { additional } \\
\text { responder }\end{array}$ & $\begin{array}{l}\text { Ferric carboxymaltose } \\
\text { more effective and } \\
\text { less costly }\end{array}$ & $\begin{array}{l}\text { CHF } 2970 \text { per } \\
\text { additional } \\
\text { responder }\end{array}$ \\
\hline \multicolumn{4}{|l|}{ TARMED costing approach } \\
\hline $\begin{array}{l}\text { Ganzoni formula used in the ferric carboxymaltose } \\
\text { arm, simplified dosing table used in iron } \\
\text { isomaltoside and iron sucrose arms }\end{array}$ & $\begin{array}{l}\text { Ferric carboxymaltose } \\
\text { more effective and } \\
\text { less costly }\end{array}$ & $\begin{array}{l}\text { Ferric carboxymaltose } \\
\text { more effective and } \\
\text { less costly }\end{array}$ & $\begin{array}{l}\text { CHF } 4574 \text { per } \\
\text { additional } \\
\text { responder }\end{array}$ \\
\hline Ganzoni formula used in all arms & $\begin{array}{l}\text { CHF } 318 \text { per } \\
\text { additional } \\
\text { responder }\end{array}$ & $\begin{array}{l}\text { Ferric carboxymaltose } \\
\text { more effective and } \\
\text { less costly }\end{array}$ & $\begin{array}{l}\text { CHF } 4574 \text { per } \\
\text { additional } \\
\text { responder }\end{array}$ \\
\hline
\end{tabular}

Response was defined as a patient who achieved normalization of hemoglobin levels or an increase in hemoglobin of at least $2 \mathrm{~g} / \mathrm{dL}$

CHF 2020 Swiss francs

IIM fell to 1.98 (from 2.00 in the base case) and the mean number of infusions required to administer IS fell to 7.02 (from 8.00 in the base case). The reduced iron dose and the reduced number of infusions resulted in reduced costs with IIM and IS compared with the base case analysis. In this analysis, FCM was associated with an ICER of CHF 45 (EUR 43) per additional responder versus IIM, but remained dominant versus IS (Table 6).

When TARMED codes were used to calculate costs of treatment, with the Ganzoni formula applied in the FCM arm and the simplified dosing table applied in the IIM and IS arms, costs increased in all treatment arms compared with the base case, but most markedly in the IS arm because of the greater number of infusions required. However, the conclusions of the analysis did not change compared with the base case, with FCM remaining dominant versus both IIM and IS. In the analysis with TARMED codes used to calculate costs and the Ganzoni formula used to calculate the iron requirement in all arms, FCM was associated with an ICER of CHF 318 (EUR 299) per additional responder versus IIM and remained dominant versus IS.

\section{Sensitivity Analyses}

Sensitivity analyses applying alternative model inputs found that results remained similar to the base case analysis (Table 7). When the upper 95\% CI of the odds ratio for achieving a response with each comparator versus FCM was applied, increased response rates with IIM 
Table 7 Sensitivity analysis results

\begin{tabular}{|c|c|c|c|}
\hline & \multicolumn{3}{|c|}{$\begin{array}{l}\text { Additional cost per additional responder with ferric carboxymaltose versus } \\
\text { the comparator }\end{array}$} \\
\hline & $\begin{array}{l}\text { Ferric carboxymaltose } \\
\text { versus iron isomaltoside }\end{array}$ & $\begin{array}{l}\text { Ferric carboxymaltose } \\
\text { versus iron sucrose }\end{array}$ & $\begin{array}{l}\text { Ferric carboxymaltose } \\
\text { versus oral iron } \\
\text { therapy }\end{array}$ \\
\hline Base case analysis & $\begin{array}{l}\text { Ferric carboxymaltose } \\
\text { more effective and less } \\
\text { costly }\end{array}$ & $\begin{array}{l}\text { Ferric carboxymaltose } \\
\text { more effective and less } \\
\text { costly }\end{array}$ & $\begin{array}{l}\text { CHF } 2970 \text { per } \\
\text { additional responder }\end{array}$ \\
\hline Upper $95 \%$ CI of odds ratios & $\begin{array}{l}\text { Ferric carboxymaltose less } \\
\text { effective and less costly }\end{array}$ & $\begin{array}{l}\text { Ferric carboxymaltose } \\
\text { equally effective and less } \\
\text { costly }\end{array}$ & $\begin{array}{l}\text { CHF } 1503 \text { per } \\
\text { additional responder }\end{array}$ \\
\hline Lower $95 \%$ CI of odds ratios & $\begin{array}{l}\text { Ferric carboxymaltose } \\
\text { more effective and less } \\
\text { costly }\end{array}$ & $\begin{array}{l}\text { Ferric carboxymaltose } \\
\text { more effective and less } \\
\text { costly }\end{array}$ & $\begin{array}{l}\text { CHF } 17,081 \text { per } \\
\text { additional responder }\end{array}$ \\
\hline Body weight increased by $10 \mathrm{~kg}$ & $\begin{array}{l}\text { Ferric carboxymaltose } \\
\text { more effective and less } \\
\text { costly }\end{array}$ & $\begin{array}{l}\text { Ferric carboxymaltose } \\
\text { more effective and less } \\
\text { costly }\end{array}$ & $\begin{array}{l}\text { CHF } 3291 \text { per } \\
\text { additional responder }\end{array}$ \\
\hline Hemoglobin increased by $1 \mathrm{~g} / \mathrm{dL}$ & $\begin{array}{l}\text { CHF } 1744 \text { per additional } \\
\text { responder }\end{array}$ & $\begin{array}{l}\text { CHF } 389 \text { per additional } \\
\text { responder }\end{array}$ & $\begin{array}{l}\text { CHF } 2608 \text { per } \\
\text { additional responder }\end{array}$ \\
\hline Hemoglobin decreased by $1 \mathrm{~g} / \mathrm{dL}$ & $\begin{array}{l}\text { CHF } 500 \text { per additional } \\
\text { responder }\end{array}$ & $\begin{array}{l}\text { Ferric carboxymaltose } \\
\text { more effective and less } \\
\text { costly }\end{array}$ & $\begin{array}{l}\text { CHF } 3445 \text { per } \\
\text { additional responder }\end{array}$ \\
\hline $\begin{array}{l}\text { Standard errors around body weight and } \\
\text { hemoglobin equal to } 10 \% \text { of the mean }\end{array}$ & $\begin{array}{l}\text { Ferric carboxymaltose } \\
\text { more effective and less } \\
\text { costly }\end{array}$ & $\begin{array}{l}\text { Ferric carboxymaltose } \\
\text { more effective and less } \\
\text { costly }\end{array}$ & $\begin{array}{l}\text { CHF } 2984 \text { per } \\
\text { additional responder }\end{array}$ \\
\hline All pharmacy costs $+10 \%$ & $\begin{array}{l}\text { Ferric carboxymaltose } \\
\text { more effective and less } \\
\text { costly }\end{array}$ & $\begin{array}{l}\text { Ferric carboxymaltose } \\
\text { more effective and less } \\
\text { costly }\end{array}$ & $\begin{array}{l}\text { CHF } 3306 \text { per } \\
\text { additional responder }\end{array}$ \\
\hline All pharmacy costs $-10 \%$ & $\begin{array}{l}\text { Ferric carboxymaltose } \\
\text { more effective and less } \\
\text { costly }\end{array}$ & $\begin{array}{l}\text { Ferric carboxymaltose } \\
\text { more effective and less } \\
\text { costly }\end{array}$ & $\begin{array}{l}\text { CHF } 2646 \text { per } \\
\text { additional responder }\end{array}$ \\
\hline
\end{tabular}

Response was defined as a patient who achieved normalization of hemoglobin levels or an increase in hemoglobin of at least $2 \mathrm{~g} / \mathrm{dL}$

CHF 2020 Swiss francs, $C I$ credible interval

(86\%), IS (81\%), and oral iron therapy (79\%) were observed, with the percentage of patients achieving a response with FCM therapy remaining unchanged from the base case (81\%). The converse effect was observed when the lower 95\% CI was applied, with the response rates for IIM, IS, and oral iron therapy falling to $59 \%, 67 \%$, and 58\%, respectively. In these two analyses, costs remained unchanged from the base case values, with FCM less costly than 
either IIM or IS, but more costly than oral iron therapy.

Increasing the mean patient body weight by $10 \mathrm{~kg}$ resulted in an increased iron requirement in all treatment arms, with mean total doses of $1493 \mathrm{mg}$ with FCM and $2000 \mathrm{mg}$ with IIM and IS. This resulted in increased costs in all treatment arms compared with the base case analysis. However, the conclusions did not change, with FCM remaining more effective and less costly compared with IIM and IS.

In the analysis with baseline hemoglobin increased by $1 \mathrm{~g} / \mathrm{dL}$, the iron requirement was reduced in all treatment arms. In the FCM arm, a mean of two infusions was required to provide the required dose of $1203 \mathrm{mg}$, but in the IIM and IS arms the required dose fell to $1000 \mathrm{mg}$, requiring one infusion with IIM and five infusions with IS to deliver this dose. In this analysis, FCM was associated with ICERs of CHF 1744 (EUR 1639) per additional responder versus IIM and CHF 389 (EUR 366) per additional responder versus IS. When the baseline hemoglobin was decreased by $1 \mathrm{mg} / \mathrm{dL}$, the iron requirement increased in the FCM arm to $1524 \mathrm{mg}$, but remained unchanged in the IIM and IS arms owing to the use of the simplified dosing table. Therefore costs increased to CHF 518 (EUR 487) per patient in the FCM arm, but remained unchanged with other therapies. FCM was associated with an ICER of CHF 500 (EUR 470) per additional responder versus IIM, but remained dominant versus IS. In the analysis with increased SEs around baseline body weight and hemoglobin, similar outcomes to the base case analysis were projected, but with increased variation in calculated costs due to a wider range of iron requirements. The conclusions of the analysis did not change, with FCM remaining dominant versus IIM and IS.

Increasing and decreasing the pharmacy costs by $10 \%$ did not change the conclusions of the analysis. FCM remained dominant versus IIM and IS in both analyses. Increasing pharmacy costs resulted in an increased ICER versus oral iron therapy, while decreasing the pharmacy costs had the converse effect.

\section{DISCUSSION}

Evaluation of the cost-effectiveness of iron treatments for patients with IDA subsequent to IBD in Switzerland has suggested that FCM is the most effective treatment option, associated with an increased number of responders (defined as patients whose hemoglobin levels are normalized or increased by at least $2 \mathrm{~g} / \mathrm{dL}$ ) compared with IIM, IS, and oral iron therapy. When FCM was compared with IIM, an equal number of infusions was required with the two formulations, but FCM was associated with a lower cost due to the lower required dose as estimated by the Ganzoni formula (in line with the Swiss product label for FCM) [17]. When FCM was compared with IS, the reduction in the number of required infusions was the key driver of cost savings with FCM, with this offsetting the increased pharmacy cost. Reducing the number of hospital or private practice visits is an important advantage from a patient perspective, as well as reducing costs for healthcare payers. Data from Switzerland suggest that IDA is more common in patients with IBD treated in a hospital outpatient setting than those treated in private practice, and therefore this information is highly pertinent to healthcare providers and patients accessing care as hospital outpatients [38]. Oral iron therapy is associated with low pharmacy costs, and the analysis confirmed that oral iron therapy was less costly than all IV iron formulations. However, oral iron therapy was found to be the least effective treatment, with the lowest response rates. Therefore decision-making is more complex, and healthcare providers must assess whether the increased efficacy of FCM compared with oral iron therapy, and the consequent improvements in anemia status, with all of the implications for comorbidities, hospitalization rates, quality of life, and time lost from work, is worth the additional cost of CHF 2970 per additional responder. However, oral iron therapy can be associated with reduced quality of life and treatment adherence as it can increase IBD-associated inflammation and cause mucosal damage and gastrointestinal symptoms. The recurrent flares of inflammation and bleeding in 
patients with IBD-related IDA result in patients requiring repeated courses of iron therapy over the long term, and therefore choosing a therapy that is both effective and cost-effective is important. The ECCO guidelines state that IV iron therapy should be considered a first-line treatment in patients with IBD who have clinically active disease, previous intolerance to oral iron therapy, a hemoglobin level below $10 \mathrm{~g} / \mathrm{dL}$, and in those who need erythropoiesis-stimulating agents [11]. While all patients with IBD should be routinely monitored for IDA, the Swiss Inflammatory Bowel Disease Cohort Study has shown that IDA is more common in female patients, those with low BMI, malabsorption syndrome, and those currently using steroids, and so particular attention should be paid to patients with IBD with these characteristics [39].

A recent publication has assessed the costeffectiveness of FCM and IIM in the UK setting based on an indirect treatment comparison, with a response defined at a hemoglobin change of at least $2 \mathrm{~g} / \mathrm{dL}$ [40]. However, the indirect comparison used in this analysis was not specific to patients with IDA, as it also included studies enrolling patients with IDA due to heavy uterine bleeding and non-dialysis-dependent chronic kidney disease. The baseline characteristics used differed from the present analysis in terms of body weight, with a mean body weight of $88.3 \mathrm{~kg}$ compared with $66.6 \mathrm{~kg}$ in the present analysis. As a result of the differences in dosing recommendations, with FCM dosage limited to a maximum of $1000 \mathrm{mg}$ per infusion irrespective of body weight, while IIM dosing is weightbased at $20 \mathrm{mg} / \mathrm{kg}$, a higher mean body weight in the analyzed cohort will favor IIM over FCM. The analysis in the UK setting is unlikely to be applicable to the population of patients with IBD in Switzerland, as it was based on data from patients with IBD due to a variety of etiologies and whose body weight is notably higher than the population of patients with IDA subsequent to IBD in Switzerland.

The present analysis used an NMA to inform the differences in efficacy between FCM, IIM, IS, and oral iron therapy, and this could be considered a weakness of the analysis [27]. This approach was chosen as, to date, no head to head RCT has included all possible treatment options for patients with IBD subsequent to IDA, although FCM and IIM were compared in an observational study conducted in patients with IBD-related IDA in Norway [21]. The primary focus of that study was safety, with efficacy measures included as secondary endpoints. FCM and IIM were also compared in two identically designed, open-label RCTs with a prespecified pooled analysis, but in $68.5 \%$ of enrolled patients the cause of IDA was a gynecological condition, rather than IBD as is of interest in the present analysis [20]. The limitations of the NMA used to inform the present analyses have been discussed by the authors of the NMA in the original publications and in post-publication correspondence [27, 41-44]. Despite its limitations, the NMA published by Aksan et al. represents the best available evidence source on differences in clinical outcomes in patients with IDA and IBD receiving IV iron therapy.

As part of the systematic review to inform the NMA, Aksan et al. also collected data on adverse event rates and found that rates of adverse events were low with all IV iron products [27]. Infusion site reactions, transient increases in liver enzymes, headache, hyperferritinemia, and hypophosphatemia were the most common adverse events. A more recently conducted NMA found that the overall incidence of adverse events was similar with all IV iron treatments, but the most frequently experienced adverse events differed between treatments [45]. With FCM and IS, the most common adverse events were headache and transient hyperferritinemia, while with IIM they were flushing, hypersensitivity, and hepatic enzyme increases. Cost-effectiveness analyses conducted in the future should aim to capture the impact of adverse events on costs and clinical outcomes.

The present analysis took a probabilistic approach, with odds ratios for achieving a response with IIM, IS, and oral iron therapy versus FCM sampled in each model iteration. This approach was chosen to reflect the uncertainty in the clinical outcomes from the NMA, where FCM was associated with a significantly greater response rate than oral iron therapy, and 
a numerically greater but not statistically significant increase in the number of responders compared with IIM and IS. As part of the probabilistic approach, patient body weight and hemoglobin were sampled and the required iron dose calculated in each model iteration. These patient characteristics were based on pooled data from two RCTs [22, 23]. An important aspect to consider is how the patients enrolled in these RCTs compare with people with IDA and IBD in Switzerland. To date, there is no Switzerland-specific real-world data that could be compared with the RCTs.

In the present study, costs and responders were assessed over one cycle of treatment for IDA, and the impact of retreatment was not included. Lack of response or recurrence of IDA due to ongoing IBD inflammation and bleeding can result in a need for retreatment [46]. If the requirement for retreatment due to non-response were to be included, costs would increase with all therapies, with the greatest impact in the least effective treatment arms. If retreatment related to recurrence of IDA were to be included, the impact on the additional cost per additional responder would likely to be minimal, as recurrence rates would be similar with all treatment arms leading to similar cost increases with all therapy options.

One of the key advantages of cost-utility analyses that assess the cost per additionally QALY gained is that the ICER produced can be compared with willingness to pay thresholds to assess whether a new intervention represents good value for money versus current practice. This allows comparison of the impact of multiple new interventions that are used in different therapeutic areas, as the calculated costs and quality-adjusted life expectancy can be directly compared. However, when a "cost per responder" approach is used, no willingness to pay thresholds have been defined, and this measure of clinical effectiveness is not applicable to other therapeutic areas. While the present analysis is the first to use a cost per responder approach in patients with IDA subsequent to IBD in Switzerland, previously published analyses have used this approach in economic analyses in other therapeutic areas in other countries, and these can provide context to the results presented here. The most pertinent analyses are those conducted in IBD generally. An analysis of the cost-effectiveness of selenium-75-homocholic acid taurine (SeHCAT) for investigation of bile acid malabsorption in chronic diarrhea in the UK setting defined a responder as a patient for whom diarrhea resolved [47]. That study found that the results were highly variable depending on the modelled population, the threshold test result for further treatment, and the assumptions applied, with results of between GBP 1208 and GBP 108,412 per additional responder. In the US setting, an analysis of biologic treatments for Crohn's disease assessed responders in terms of a patient with a decrease in Crohn's Disease Activity Index (CDAI) score of at least 70 points from baseline, and a remitter as a patient with a CDAI score of less than 150 [48]. Cost per responder and cost per remitter varied with the differing interventions, with the modelling analysis suggesting that the additional cost per additional responder was USD 116,291 for adalimumab versus placebo and USD 125,169 for infliximab versus placebo, and that the additional cost per additional remitter was USD 121,863 for adalimumab versus placebo and USD 174,846 for infliximab versus placebo. However, such analyses are not limited to IBD, with cost per responder analyses previously conducted to assess the cost-effectiveness of treatments for glioblastoma, rheumatoid and psoriatic arthritis, chronic obstructive pulmonary disease, chronic immune thrombocytopenia, and psoriasis [49-53].

\section{CONCLUSIONS}

The present cost-effectiveness analysis is the first study to compare the cost-effectiveness of IV and oral iron treatment for patients with IDA subsequent to IBD in Switzerland. The results suggest that FCM is likely to be the most effective intervention, with the highest percentage of patients achieving a response. Furthermore, FCM was less costly than both IIM and IS. Oral iron therapy is associated with low pharmacy costs, and the analysis confirmed that oral iron therapy was less costly than all IV iron 
formulations. However, oral iron therapy was found to be the least effective treatment, with the lowest response rates, and this effect is likely to be greater in real-world clinical practice because of the gastrointestinal side effects and subsequent poor adherence. Oral iron therapy is a suitable treatment option only for patients with mild IDA and clinically inactive IBD, with no history of intolerance to oral iron therapy, and therefore the target population is likely to be different to the target population of IV iron therapies. FCM was projected to be the most cost-effective IV iron therapy in Switzerland, increasing the number of responders and leading to cost savings for healthcare payers.

\section{ACKNOWLEDGEMENTS}

Funding. The study, the journal's Rapid Service and Open Access fees were supported by funding from Vifor Pharm Group.

Authorship. All named authors meet the International Committee of Medical Journal Editors (ICMJE) criteria for authorship for this article, take responsibility for the integrity of the work as a whole, and have given their approval for this version to be published.

Disclosures. Aysegül Aksan has received consulting or speaker fees from the following Immundiagnostik and Vifor Pharma, and research funding from Immundiagnostik. Alain Schoepfer has received consulting or speaker fees from the following companies: Abbvie, Dr Falk Pharma, MSD, Pfizer, Regeneron, Takeda, UCB, and Vifor Pharma. Pascal Juillerat declared no conflict of interest. Stephan Vavricka has received consulting or speaker fees from the following companies: Abbvie, Dr Falk Pharma, Ferring, Gilead, iQuone, Janssen, MSD, Pierre Fabre, Pfizer, Regeneron, Sanofi, Takeda, Tillotts, UCB, and Vifor Pharma. Miguel Bettencourt, Antonio Ramirez de Arellano, Simona Gavata and Neige Morin are employees of Vifor Pharma Group. William J Valentine and Barnaby Hunt are employees of Ossian Health Economics and Communications, which received consulting fees from Vifor Pharma Group to support preparation of the analysis.

Compliance with Ethics Guidelines. This article is based on previously conducted studies and does not contain any studies with human participants or animals performed by any of the authors,

Data Availability. The datasets generated during and/or analyzed during the current study are available from the corresponding author on reasonable request.

Open Access. This article is licensed under a Creative Commons Attribution-NonCommercial 4.0 International License, which permits any non-commercial use, sharing, adaptation, distribution and reproduction in any medium or format, as long as you give appropriate credit to the original author(s) and the source, provide a link to the Creative Commons licence, and indicate if changes were made. The images or other third party material in this article are included in the article's Creative Commons licence, unless indicated otherwise in a credit line to the material. If material is not included in the article's Creative Commons licence and your intended use is not permitted by statutory regulation or exceeds the permitted use, you will need to obtain permission directly from the copyright holder. To view a copy of this licence, visit http://creativecommons.org/licenses/bync/4.0/.

\section{REFERENCES}

1. GBD 2017 Inflammatory Bowel Disease Collaborators. The global, regional, and national burden of inflammatory bowel disease in 195 countries and territories, 1990-2017: a systematic analysis for the Global Burden of Disease Study 2017. Lancet Gastroenterol Hepatol. 2020;5(1):17-30.

2. Juillerat P, Pittet V, Bulliard JL, et al. Prevalence of inflammatory bowel disease in the Canton of Vaud (Switzerland): a population-based cohort study. J Crohns Colitis. 2008;2(2):131-41.

3. Bähler C, Vavricka SR, Schoepfer AM, Brüngger B, Reich O. Trends in prevalence, mortality, health 
care utilization and health care costs of Swiss IBD patients: a claims data based study of the years 2010, 2012 and 2014. BMC Gastroenterol. 2017;17(1):138.

4. Gasche C. Complications of inflammatory bowel disease. Hepatogastroenterology. 2000;47(31): 49-56.

5. Wells CW, Lewis S, Barton JR, Corbett S. Effects of changes in hemoglobin level on quality of life and cognitive function in inflammatory bowel disease patients. Inflamm Bowel Dis. 2006;12(2):123-30.

6. Stein J, Dignass AU. Management of iron deficiency anemia in inflammatory bowel disease-a practical approach. Ann Gastroenterol. 2013;26(2):104-13.

7. Kulnigg S, Gasche C. Systematic review: managing anaemia in Crohn's disease. Aliment Pharmacol Ther. 2006;24(11-12):1507-23.

8. Nielsen $\mathrm{OH}$, Ainsworth $\mathrm{M}$, Coskun M, Weiss G. Management of iron-deficiency anemia in inflammatory bowel disease: a systematic review. Medicine. 2015;94:e963.

9. Camaschella C. Iron-deficiency anemia. N Engl J Med. 2015;372:1832-43.

10. Gomollón F, Gisbert JP. Anemia and inflammatory bowel diseases. World J Gastroenterol. 2009;15(37): 4659-65.

11. Dignass AU, Gasche C, Bettenworth D, et al. European consensus on the diagnosis and management of iron deficiency and anaemia in inflammatory bowel diseases. J Crohns Colitis. 2015;9(3):211-22.

12. Kaitha S, Bashir M, Ali T. Iron deficiency anemia in inflammatory bowel disease. World J Gastrointest Pathophysiol. 2015;6(3):62-72.

13. Carrier J, Aghdassi E, Cullen J, Allard JP. Iron supplementation increases disease activity and vitamin E ameliorates the effect in rats with dextran sulfate sodium-induced colitis. J Nutr. 2002;132:3146-50.

14. Carrier J, Aghdassi E, Platt I, Cullen J, Allard JP. Effect of oral iron supplementation on oxidative stress and colonic inflammation in rats with induced colitis. Aliment Pharmacol Ther. 2001;15: 1989-99.

15. Erichsen K, Hausken T, Ulvik RJ, Svardal A, Berstad A, Berge RK. Ferrous fumarate deteriorated plasma antioxidant status in patients with Crohn disease. Scand J Gastroenterol. 2003;38:543-8.

16. Mahalhal A, Williams JM, Johnson S, et al. Oral iron exacerbates colitis and influences the intestinal microbiome. PLoS One. 2018;13(10):e0202460.
17. Compendium.ch. FERINJECT Inj Lös $100 \mathrm{mg} / 2 \mathrm{ml}$. https://compendium.ch/product/1080875ferinject-inj-los-100-mg-2ml/mpro. Accessed 17 July 2020.

18. Compendium.ch. MONOFER Inj Inf Präp $100 \mathrm{mg} /$ $\mathrm{ml}$ (iH 12/19). https://compendium.ch/product/ 1423093-monofer-inj-inf-prap-100-mg-ml/mpro. Accessed 17 July 2020.

19. Compendium.ch. VENOFER Inj Lös $100 \mathrm{mg} / 5 \mathrm{~m}$. https://compendium.ch/product/46040-venoferinj-los-100-mg-5ml/mpro. Accessed 17 July 2020.

20. Wolf M, Rubin J, Achebe M, et al. Effects of iron isomaltoside vs ferric carboxymaltose on hypophosphatemia in iron-deficiency anemia: two randomized clinical trials. JAMA. 2020;323(5): 432-43.

21. Detlie TE, Lindstrøm JC, Jahnsen ME, et al. Incidence of hypophosphatemia in patients with inflammatory bowel disease treated with ferric carboxymaltose or iron isomaltoside. Aliment Pharmacol Ther. 2019;50(4):397-406.

22. Evstatiev R, Marteau P, Iqbal T, et al. FERGIcor, a randomized controlled trial on ferric carboxymaltose for iron deficiency anemia in inflammatory bowel disease. Gastroenterology. 2011;141(3): 846-853.e1-2.

23. Kulnigg S, Stoinov S, Simanenkov V, et al. A novel intravenous iron formulation for treatment of anemia in inflammatory bowel disease: the ferric carboxymaltose (FERINJECT) randomized controlled trial. Am J Gastroenterol. 2008;103(5): 1182-92.

24. Lindgren S, Wikman O, Befrits $\mathrm{R}$, et al. Intravenous iron sucrose is superior to oral iron sulphate for correcting anaemia and restoring iron stores in IBD patients: a randomized, controlled, evaluator-blind, multicentre study. Scand J Gastroenterol. 2009;44(7):838-45.

25. Reinisch W, Staun M, Tandon RK, et al. A randomized, open-label, non-inferiority study of intravenous iron isomaltoside 1,000 (Monofer) compared with oral iron for treatment of anemia in IBD (PROCEED). Am J Gastroenterol. 2013;108(12): 1877-88.

26. Schröder O, Mickisch O, Seidler U, et al. Intravenous iron sucrose versus oral iron supplementation for the treatment of iron deficiency anemia in patients with inflammatory bowel disease-a randomized, controlled, open-label, multicenter study. Am J Gastroenterol. 2005;100(11):2503-9.

27. Aksan A, Işık H, Radeke HH, Dignass A, Stein J. Systematic review with network meta-analysis: 
comparative efficacy and tolerability of different intravenous iron formulations for the treatment of iron deficiency anaemia in patients with inflammatory bowel disease. Aliment Pharmacol Ther. 2017;45(10):1303-18.

28. Nuijten MJ, Dubois DJ. Cost-utility analysis: current methodological issues and future perspectives. Front Pharmacol. 2011;2:29.

29. Khunti K, Gillies CL, Taub NA, et al. A comparison of cost per case detected of screening strategies for type 2 diabetes and impaired glucose regulation: modelling study. Diabetes Res Clin Pract. 2012;97(3):505-13.

30. Katz P, Showstack J, Smith JF, et al. Costs of infertility treatment: results from an 18-month prospective cohort study. Fertil Steril. 2011;95(3): 915-21.

31. Bundesamt für Gesundheit BAG. Spezialitätenliste (SL): Index der SL-Verzeichnisse. http://www.xnspezialittenliste-yqb.ch/. Accessed 17 July 2020.

32. Lohnanalyse. Krankenschwester/Krankenpfleger in der Schweiz. https://www.lohnanalyse.ch/ch/ loehne/details/krankenschwesterkrankenpfleger. html. Accessed 17 July 2020.

33. Kuhn und Bieri AG. BUTTERFLY/FLÜGELKANÜLE LL 21G, (0.8X19MM), GRÜN, LEITUNG: 30CM, STERIL. https://www.kuhnbieri.ch/de/butterflyflugelkanule-1l-21g-0-8x19mm-grun-leitung-30cmsteril.html. Accessed 17 July 2020.

34. Shop Apotheke. Venofix ${ }^{\circledR}$ A 0,8/G21. https://www. shop-apotheke.ch/de/gesundheit/5039573/venofixa-0-8-g21.htm. Accessed 17 July 2020.

35. Shop Apotheke. LEUKOMED sterile Pflaster $7.2 \times 5$ cm. https://www.shop-apotheke.ch/de/gesundheit/ 1050922/leukomed-7-2-cm-x-5-cm-steril.htm. Accessed 17 July 2020.

36. RTS Info. Une étude révèle ce que gagnent les médecins en Suisse. https://www.rts.ch/info/suisse/ 9953104-une-etude-revele-ce-que-gagnent-lesmedecins-en-suisse.html. Accessed 17 July 2020.

37. FMH- Berufsverband. TARMED. https://www.fmh. ch/themen/ambulante-tarife/tarmed.cfm. Accessed 17 July 2020.

38. Voegtlin M, Vavricka SR, Schoepfer AM, et al. Prevalence of anaemia in inflammatory bowel disease in Switzerland: a cross-sectional study in patients from private practices and university hospitals. J Crohns Colitis. 2010;4(6):642-648.

39. Madanchi M, Fagagnini S, Fournier N, et al. The relevance of vitamin and iron deficiency in patients with inflammatory bowel diseases in patients of the swiss IBD Cohort. Inflamm Bowel Dis. 2018;24(8): 1768-1779.

40. Pollock RF, Muduma G. A patient-level cost-effectiveness analysis of iron isomaltoside versus ferric carboxymaltose for the treatment of iron deficiency anemia in the United Kingdom. J Med Econ. 2020;23(7):751-9.

41. Kennedy NA, Goodhand JR, Rampton DS. Editorial: which iron preparation for patients with IBD? Aliment Pharmacol Ther. 2017;46(2):194-5.

42. Aksan A, Işık H, Radeke HH, Dignass A, Stein J. Editorial: which iron preparation for patients with IBD? Authors' reply. Aliment Pharmacol Ther. 2017;46(2):195-6.

43. Reinisch W, Lindgren S. Letter: the importance of dosing and baseline haemoglobin when establishing the relative efficacy of intravenous iron therapies. Aliment Pharmacol Ther. 2017;46(7):704-5.

44. Aksan A, Işık H, Radeke HH, Dignass A, Stein J. Letter: the importance of dosing and baseline haemoglobin when establishing the relative efficacy of intravenous iron therapies-authors' reply. Aliment Pharmacol Ther. 2017;46(7):705-6.

45. Aksan A, Işık H, Aksan S, Tuğal D, Dignass A, Stein JM. P585 Evaluation and comparison of the safety profiles of different intravenous iron preparations and oral iron for treatment of iron deficiency anaemia: preliminary results from the IBD subgroup analysis. J Crohn's Colitis. 2020;14(Supplement_1):S490-S490.

46. Kulnigg S, Teischinger L, Dejaco C, Waldhör T, Gasche C. Rapid recurrence of IBD-associated anemia and iron deficiency after intravenous iron sucrose and erythropoietin treatment. Am J Gastroenterol. 2009;104(6):1460-7.

47. Riemsma R, Al M, Corro Ramos I, et al. SeHCAT [tauroselcholic (selenium-75) acid] for the investigation of bile acid malabsorption and measurement of bile acid pool loss: a systematic review and costeffectiveness analysis. Health Technol Assess 2013;17(61):1-236.

48. Liu Y, Wu EQ, Bensimon AG, et al. Cost per responder associated with biologic therapies for Crohn's disease, psoriasis, and rheumatoid arthritis. Adv Ther. 2012;29(7):620-34.

49. Baguet T, Verhoeven J, De Vos F, Goethals I. Costeffectiveness of [18F] fluoroethyl-L-tyrosine for temozolomide therapy assessment in patients with glioblastoma. Front Oncol. 2019;9:814. 
50. Wehler E, Boytsov N, Nicolay C, Herrera-Restrepo $\mathrm{O}$, Kowal S. A budget impact and cost per additional responder analysis for baricitinib for the treatment of moderate-to-severe rheumatoid arthritis in patients with an inadequate response to tumor necrosis factor inhibitors in the USA. Pharmacoeconomics. 2020;38(1):39-56.

51. Strand V, Elaine Husni M, Betts KA, et al. Network meta-analysis and cost per responder of targeted immunomodulators in the treatment of active psoriatic arthritis. BMC Rheumatol. 2018;2:3.
52. Rajagopalan K, Bloudek L, Marvel J, Dembek C, Kavati A. Cost-effectiveness of twice-daily indacaterol/glycopyrrolate inhalation powder for the treatment of moderate to severe COPD in the US. Int J Chron Obstruct Pulmon Dis. 2018;13: 3867-3877.

53. Armstrong AW, Betts KA, Sundaram M, Thomason D, Signorovitch JE. Comparative efficacy and incremental cost per responder of methotrexate versus apremilast for methotrexate-naïve patients with psoriasis. J Am Acad Dermatol. 2016;75(4): 740-746. 